\title{
Discussion
}

of

"Ten Years Experience with the Swiss National Bank Monetary Policy

Strategy" by T. Jordan, M. Peytringnet and E. Rossi

MARVIN GOODFRIEND ${ }^{a}$

As one who has long favored the explicit targeting of low inflation, I welcome the opportunity to comment on the Swiss National Bank's new monetary policy strategy, a framework that puts at its core an explicit definition of price stability - any non-negative inflation rate under 2 percent. The paper is a thorough review of the new strategy in practice since it was adopted in December 1999. It is a comprehensive "case study" that covers 1) the perceived need for a new strategy, 2) the components of the strategy, 3) its relationship to "inflation targeting," 3) its flexibility, 4) the tactics of interest-rate policy actions, 5) critical policy decisions during the period, 6) consequences for the marcoeconomy, and 7) new measures taken to steer and support the money market during the recent financial turmoil. Finally, the paper includes a self-assessment of various aspects of the new strategy in light of the decade's experience, giving special consideration to the definition of price stability, the operational interest-rate target, the use of information, the publication of the inflation forecast, SNB transparency, and the flexibility of the strategy.

Seldom does one see the publication by the leadership of a central bank of a comprehensive, detailed overview of recent monetary policy conducted by that central bank. The SNB should be commended for producing this timely selfassessment. The paper should take its place in the academic literature on central banking as one of the few nearly contemporaneous comprehensive inside accounts of monetary policy.

The authors emphasize that the new strategy is not a departure, but merely continues the longstanding SNB priority for low inflation. ${ }^{1}$ To put it another way, one might say that the new strategy builds on and extends the SNB's "credibility for low inflation." Hence, I will assess the new strategy by pointing out those

a Presented at the Swiss National Bank conference "The SNB's New Monetary Policy Framework Ten Years On," held October 29-30, 2009, in Swiss Re Centre for Global Dialogue, Rüschlikon, Switzerland.

1 Rich (1997). 
features apt to secure that credibility and those features apt to put that credibility at risk by allowing for enhanced flexibility.

\section{The Inflation Objective}

The authors describe the transition from monetary targeting to the new strategy as a move from an implicit definition of price stability "veiled in the money supply targets" to an explicit inflation objective. In other words, the move appears to have been undertaken to secure the credibility for low inflation. However, the announced explicit long-run inflation objective, "a rise in the consumer price index (CPI) of less than 2 percent," is less explicit than it could have been in the sense that it is a range rather than a point target. Presumably, the range allows for long-run inflation to settle anywhere from zero to two percent.

This aspect of the new strategy seems to reflect a willingness to sacrifice longrun market guidance in order to allow more flexibility. A long run point target for inflation is compatible with a range to allow for medium-term fluctuations in inflation. What is the need for flexibility in long run inflation? Why not give markets a clear point of reference for long run inflation expectations? The SNB is apparently more comfortable with the range rather than a point because no fine-tuning of inflation is intended and because of measurement error, but these would seem to be medium-term concerns, and, don't explain why one would want to allow for some variance in long run inflation expectations.

\section{Published Inflation Forecasts}

In order to provide market guidance on the course of monetary policy, the SNB publishes explicit inflation forecasts with a three-year horizon on a quarterly basis, conditional on the level of the 3-month Libor interest rate target decided at the last monetary policy assessment remaining unchanged for the forecast horizon. The SNB emphasizes that the published inflation forecasts are consensual, meaning that they involve a blend of inputs - from various statistical and structural models, from monetary indicators, and from the judgment of SNB staff. The SNB utilizes such inflation forecasts as the chief communication vehicle in communicating the likely direction of future interest rate decisions.

It is easy to criticize such published forecasts on the grounds that they will not be efficient forecasts of the inflation rate. In fact, such projections are likely to be serially correlated relative to market forecasts. For instance, an elevated 
published forecast of inflation that elicits a tightening of monetary policy can be expected to be biased upward ex post. The routine publication of such inflation forecasts could give the impression of greater uncertainty in actual inflation, possibly destabilizing short run inflation expectations.

Should one be concerned that such published forecasts are potentially misleading and counterproductive? Given the SNB's credibility for low inflation, there would appear to be little reason for concern. In such an environment inflation is expected to be well-behaved, and the SNB's published inflation "forecasts" are likely to be taken for what they are, not as efficient forecasts, but as guidance on the medium term interest rate policy "intentions" of the SNB. Moreover, such published inflation "forecasts" in and of themselves have the virtue of foreshadowing and explaining why the SNB is inclined to raise or lower interest rates in the future. Such "forecasts" provide a simple, direct means of alerting and preparing the general public for its interest rate policy actions.

Instead, the SNB could publish truly efficient inflation forecasts, and find another means of communicating its policy intentions. For instance, the SNB could publish a path for future short-term interest rates that it expects to implement, but these would not explain the reasons for its interest rate policy actions. Interest rate paths would need to be accompanied by an announced concern for inflation, real output, or perhaps the exchange rate.

Given the SNB's credibility for low inflation, one communication device is about as good as another, and so the SNB might as well communicate with its all-in-one published inflation forecast. The important thing is to maintain what I would call "dynamic accountability," the inflation forecast must be followed ex post with short-term interest rate policy actions on average that preserve the ex ante power of the inflation forecast to move expected future short term interest rates as intended.

\section{Operating Procedures}

The SNB implements interest rate policy by setting a target range for the Swiss franc 3 -month Libor (normally 1 percentage point wide) in conjunction with an announcement about which part of the going range the SNB prefers. The current policy "stance" is a "range" to allow an expected future change of policy to be accommodated within the current stance. The 3-month Libor is the offered rate for unsecured loans between prime banks in London. The SNB targets this offshore rate because it serves as the benchmark for pricing most Swiss franc debt instruments relevant for Swiss firms and households. 
The 3-month Libor normally is linked closely to overnight and 1-week Repo rates via the expectations theory of the term structure of interest rates (given the term premium). The SNB manages the scarcity of bank reserves in Switzerland to steer Repo rates to support its 3-month Libor target. For instance, by lending against Repo collateral, the SNB adds reserves to the Swiss banking system, thereby lowering the current and expected future Repo rates and thus 3-month Libor. To protect itself against losses and to ensure equal treatment of business partners, collateral eligible for SNB Repos are denominated in Swiss francs and foreign currencies and must meet certain liquidity and credit-rating criteria.

These operating procedures offer flexibility that the SNB exploits to advantage. First, the SNB utilizes the target range for 3-month Libor to respond flexibly to exchange rate shocks without signaling an immediate change in its basic policy orientation. Second, the SNB is able to insulate its policy stance from a rise in the risk premium in 3-month Swiss-franc Libor by lowering its Repo rate.

One might think that the transmission of monetary policy through an off-shore market needlessly exposes Swiss monetary policy to external forces, although experience has shown that the SNB is able to tightly manage 3-month Swissfranc Libor, despite its being an offshore rate. That said, the SNB promoted the Repo market in Switzerland in the early 2000s to facilitate its new strategy. Hence, one would think that the SNB could promote a more direct transmission of its interest rate policy to the Swiss economy by facilitating the development of a domestic short-term money market reference rate. After all, under the new strategy the SNB sets short-term Swiss franc interest rates, essentially providing its "own reference rate" for Swiss franc credit markets. Why couldn't a means be found to secure the transmission of interest rate policy domestically?

The SNB highlights the flexibility of its operating procedures - in the Repo rate, allotment volume, maturity (usually one week) and frequency (usually daily), in addition to the abovementioned advantages. At some point, however, one would think that flexibility could impair transparency, and degrade credibility for managing future short rates and inflation. A central bank, even the SNB, must be careful that "discretionary flexibility" does not come to be regarded with suspicion by the market, especially if there is reason to fear that the central bank might be tempted to obfuscate its handling of conflicting, or unpopular, short run objectives. The SNB must discipline itself to utilize flexibility sparingly so as not to jeopardize the overall credibility of its operating procedures. 


\section{Monitoring Inflation Expectations}

Judging by favorable inflation outcomes in recent years, it seems indisputable that the SNB has credibility for low inflation. Nevertheless, the paper presents no concrete evidence of market-based inflation expectations from survey data or as implied by market interest rates. One wonders how survey or market-based measures of inflation expectations behaved since 1999 compared to the previous period of monetary targeting. The SNB's credibility for low inflation might have obviated the need for surveys of inflation expectations, or an index bond market in Swiss francs. In this case, the SNB should consider subsidizing such indicators to build an "early warning system" against rising or falling inflation expectations.

\section{Tactics of Interest Rate Policy}

The paper reports that the SNB has exhibited complete reversal aversion with regard to changing the 3 -month Libor operating target. Interest rate changes once undertaken were seldom quickly reversed and instead continued on what one might call "interest rate campaigns." From the theoretical perspective, avoiding reversals makes a larger fraction of a given change in the short-term interest rate carry forward into expected future short-term interest rates, and thus exerts a larger influence on longer-term interest rates. Reversal aversion is desirable because it minimizes the variability of short-term interest rates for given leverage over longer-term interest rates. ${ }^{2}$ Avoiding interest rate policy reversals is particularly useful when there is a low inflation premium and nominal interest rates are near zero on average. That said, one wonders whether the SNB has thought in such terms in the implementation of interest rate policy.

A second tactical inclination emphasized in the paper is that if inflation temporarily exceeds the 2 percent ceiling in extraordinary circumstances, for example, following a sudden massive rise in oil prices or strong exchange rate appreciation, the stance of interest rates is not necessarily adjusted. In other words, it would appear that the SNB implicitly targets a "core" measure of sticky prices in the medium run, passing through to the price level one-time changes in flexible prices of oil or imported goods prices via an exchange rate shock.

Modern consensus theory suggests that a central bank with credibility for low inflation should target core rather than headline inflation in the medium term.

2 Goodfriend (1991) and Woodford (2003). 
So the SNB behaves as one might expect in this regard. To do otherwise, monetary policy would react to a rise in flexible prices by depressing aggregate demand and employment in the sticky price sector to produce an offsetting decline in sticky prices. That would be inefficient. Modern macroeconomic theory says that monetary policy should make the economy operate as if all prices were fully flexible. And that principle is best achieved by targeting core rather than headline inflation, and letting the economy adjust to changes in relative flexible prices, while core inflation and employment are both stabilized. ${ }^{3}$

The paper emphasizes, however, that the SNB does not necessarily react systematically to core inflation, core inflation measures being just one of an array of indicators taken into account in shaping an overall picture of underlying inflation pressures. In other words, the SNB wishes to keep its options open. But this has a potential cost. The reluctance on the part of a central bank to specify more clearly, in principle at least, how it intends to react to rising inflation runs the risk of confusing markets at a minimum, or worse, generating an inflation scare. The SNB may be correct that the assertion of such flexibility with regard to rising inflation will not undermine its credibility for low inflation. Nevertheless, there is a limit beyond which credibility could be undermined by excessively discretionary behavior.

This issue illustrates the two poles of behavior that a central bank must choose between in practice. At one pole the central bank announces its intention to follow a tightly specified rule, with the risk that any deliberate or inadvertent departures from the rule will weaken credibility. At the other pole, the central bank's policy rule is not specified clearly with the risk that policy can come to be seen as excessively discretionary and without credibility. The problem is that a central bank such as the SNB that has earned credibility for low inflation is inevitably tempted to move toward the second pole.

\section{Complications in the Credit Turmoil}

The credit turmoil beginning in the summer of 2007 presented the SNB with unprecedented problems in the implementation of monetary policy. The SNB responded creatively. The first problem was that the financial market put a significant risk premium between the unsecured 3-month Swiss-franc Libor and the Repo rate. The SNB responded initially by reducing the Swiss-franc Repo

3 Goodfriend (2007). 
rate to make room for the elevated risk premium. Thereby, the SNB stabilized its key policy rate, 3-month Swiss-franc Libor, with a quiet behind-the-scenes reduction of the Repo rate. The SNB emphasizes the advantage of separating its operational interest rate policy instrument (Repo) from the key policy rate (Libor). Such separation minimizes confusion that could otherwise occur in the presence of elevated credit spreads when the interest rate policy instrument is the same as the key targeted interest rate, as in the Euro area and in the United States.

However, there is a potential problem. Ordinarily, credit-spread fluctuations help the price system to equilibrate supply and demand in credit markets. A wider credit spread is a way for borrowers to induce a continuing flow of credit in periods of elevated actual or perceived financial risk. Preventing unsecured Libor from rising with its credit spread can be counterproductive if doing so blunts the response of credit supply to credit demand.

From the perspective of macroeconomic theory, a given credit disruption will call for a reduction in the riskless short-term (Repo) rate in so far as it reduces the underlying "natural rate of interest," the riskless interest rate consistent with maintaining full employment and price stability. In principle, elevated credit spreads can be associated with more or less of an offsetting decline in the natural rate depending on the macroeconomic nature of underlying shock. Recent work incorporating money and banking into empirical models of the economy will help to assess what Repo rate adjustments are called for in response to creditspread shocks.

A second problem faced by the SNB is that banks in Eastern Europe had granted Swiss-franc denominated loans on a massive scale, partly refinancing themselves on the money markets. During the crisis, many Swiss banks were no longer prepared to supply funds to refinance these loans at the going interest rate. So the SNB has been making Swiss-franc credit available to banks in need of such funding through various channels. The SNB began to issue its own debt, SNB Bills, in October 2008 to finance this "credit policy," without creating reserves which would have pushed the Repo rate to zero.

It is interesting to compare the responses of the Fed and SNB in the fall of 2008. Both central banks pursued "credit policies" in response to the credit turmoil. Both were concerned that funding their respective "credit" initiatives by creating bank reserves would push their policy interest rates to zero. Each approached the problem differently. The Fed asked for authority to pay interest on reserves to help put a floor under the federal funds rate as it created hundreds of billions of dollars of bank reserves to fund its credit policy initiatives. The $\mathrm{SNB}$, however, did not have the authority to pay interest on reserves. Instead, it began to issue its own short-term non-monetary liabilities, SNB Bills, to fund 
its credit policy initiatives without adding reserves to the banking system. Thus did the two central banks solve the same policy problem in different operational ways suited to their own circumstances.

Another major problem faced by the SNB was the huge "safe haven" demand for Swiss francs. The SNB regarded the 10\% appreciation of the Swiss franc against the Euro from September 2008 to March 2009 as a deflationary threat to the Swiss economy. The SNB responded by pushing its target Repo rate down to the zero bound. And in March 2009 the SNB purchased foreign currency for the first time in 15 years. The SNB financed its foreign exchange purchases with freshly-created bank reserves, pushing aggregate reserves beyond the level necessary to keep interest rates at zero.

The SNB appears to regard its foreign exchange intervention as a success in that the appreciation trend of the Swiss franc was broken as intended. But this leaves some interesting and important questions unanswered. For instance, one would like to know how the SNB thinks that its foreign exchange intervention worked: was it through the purchase of foreign securities, or was the intervention effective because it involved the creation of unsterilized bank reserves beyond those needed to push short term interest rates to zero? In both cases, one would like to know through what channels the SNB believes its foreign exchange intervention worked at the zero bound. In particular, does the evidence suggest that foreign exchange interventions are more effective at the zero bound because they can be financed with unsterilized bank reserves?

\section{Conclusion}

As discussed at the outset, the SNB insists that it does not target inflation close to 2 percent, but rather that it is satisfied with inflation anywhere in the 0 to 2 percent range. One might think, then, that the SNB is confident in the effectiveness of its "balance sheet" policy at the zero bound. Otherwise, one might expect the SNB to target inflation near $2 \%$ to reduce the chance of hitting the zero bound by securing a $2 \%$ inflation premium in the nominal interest rate. The apparently successful unsterilized foreign exchange intervention mentioned above suggests a degree of confidence in balance sheet policy at the zero bound. Moreover, the SNB's longstanding confidence in the power of monetary policy to stabilize inflation and employment might be expected to hold regardless of the zero bound. The SNB should reconcile its flexible inflation objective with its beliefs about the power of monetary policy at the zero bound. 


\section{References}

Goodfriend, Marvin (1991), "Interest Rates and the Conduct of Monetary Policy", Carnegie Rochester Conference Series on Public Policy, 34 (Spring), pp. 7-30.

Goodfriend, Marvin (2007), "How the World Achieved Consensus on Monetary Policy", Journal of Economic Perspectives, 21 (4), pp.47-68.

Rich, Georg (1997), "Monetary Targets as a Policy Rule: Lessons from the Swiss Experience", Journal of Monetary Economics, 39 (1), pp. 113-141.

Woodford, Michael (2003), "Optimal Interest-Rate Smoothing", Review of Economic Studies 70 (4), pp. 861-886. 